\title{
Percutaneous coronary intervention of a single coronary artery arising from the right sinus of Valsalva
}

This article was published in the following Dove Press journal:

Vascular Health and Risk Management

24 November 2010

Number of times this article has been viewed

\author{
Mehmet Akif Cakar \\ Ersan Tatli \\ Bilhan Ozalp ${ }^{2}$ \\ Huseyin Gunduz' \\ 'Sakarya Education and Research \\ Hospital, Cardiology Department, \\ Sakarya, Turkey; ${ }^{2}$ Ada Tip Private \\ Hospital, Cardiology Department, \\ Korucuk, Sakarya, Turkey
}

\begin{abstract}
Anomalous origin of the left main coronary artery from the right sinus of Valsalva is extremely rare when not associated with other congenital cardiac anomalies. In this report we present a patient with a single coronary ostium, with both the left and right coronary artery systems arising from it. The right coronary artery was found to contain a significant flow-limiting lesion that was successfully treated with percutaneous coronary intervention.
\end{abstract}

Keywords: single coronary artery, percutaneous coronary intervention

\section{Introduction}

Anomalous origin of the left main coronary artery from the right sinus of Valsalva is extremely rare when not associated with other congenital cardiac anomalies. They are seen in $0.3 \%-1.3 \%$ of patients undergoing coronary angiography and in $0.17 \%$ of routine autopsy studies. ${ }^{1}$ In this report we present a patient with a single coronary ostium, with both the left and right coronary artery (RCA) systems arising from it and then following their usual courses. This case was diagnosed incidentally during conventional angiography. The RCA was found to contain a significant flow-limiting lesion that was successfully treated with percutaneous coronary intervention (PCI).

\section{Case presentation}

A 68-year-old male was admitted to our hospital for evaluation of intermittent atypical chest pain for several months. He had a history of hypertension and diabetes. His blood pressure was 130/80 $\mathrm{mmHg}$ and the pulse rate was 72 beats/minute. His electrocardiography (ECG) was normal. Treadmill exercise electrocardiograms revealed ischemic changes accompanied by chest pain. Therefore, the patient was referred for coronary angiography. Selective coronary angiography was performed via the right femoral approach (Seldinger technique). Angiography showed no vessels originating from the left coronary sinus (CS). Left main coronary artery (LMCA) originating from the proximity of the RCA and dividing into left anterior descending and left circumflex artery was shown and a diffuse $70 \%$ lesion in the midsegment of the RCA, which was the presumed cause of the patient's angina (Figure 1A, B). We performed PCI and stenting of this lesion (Figure 2).

\section{Discussion}

Single coronary artery (SCA) is a rare congenital abnormality characterized by a common origin of both the right and left coronary arteries from a single aortic ostium. ${ }^{2}$ 
A

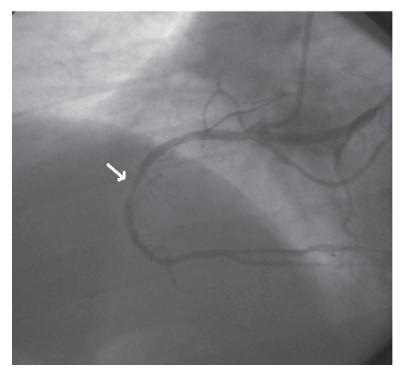

B

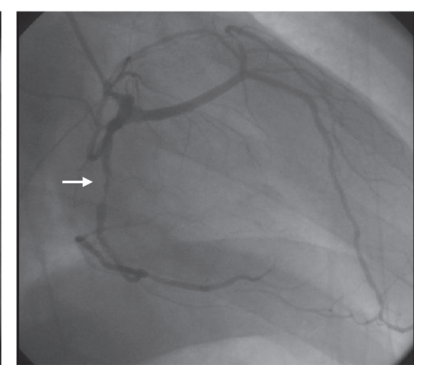

Figure I A) The left anterior descending artery does not originate from left coronary sinus but can be followed to the right atrioventricular groove, where it originates from the right coronary artery. B) Figures demonstrate the $70 \%$ right coronary artery lesion (white arrow).

Several classification systems for coronary artery abnormalities exist. Lipton et al classified coronary variations based on origin and anatomical course relating to the ascending aorta and pulmonary trunk. ${ }^{3}$ In the present case, after its origin the main trunk divides into the right and left main arteries or into right coronary artery, left anterior descending coronary artery, and circumflex artery. The SCA anomaly is usually asymptomatic, but may present as myocardial ischemia, syncope, or sudden cardiac death depending on its course and the presence and severity of atherosclerosis. ${ }^{4}$ There is no consensus regarding the risk for atherosclerosis in SCA cases. The literature includes variable reports. Porto et al claim

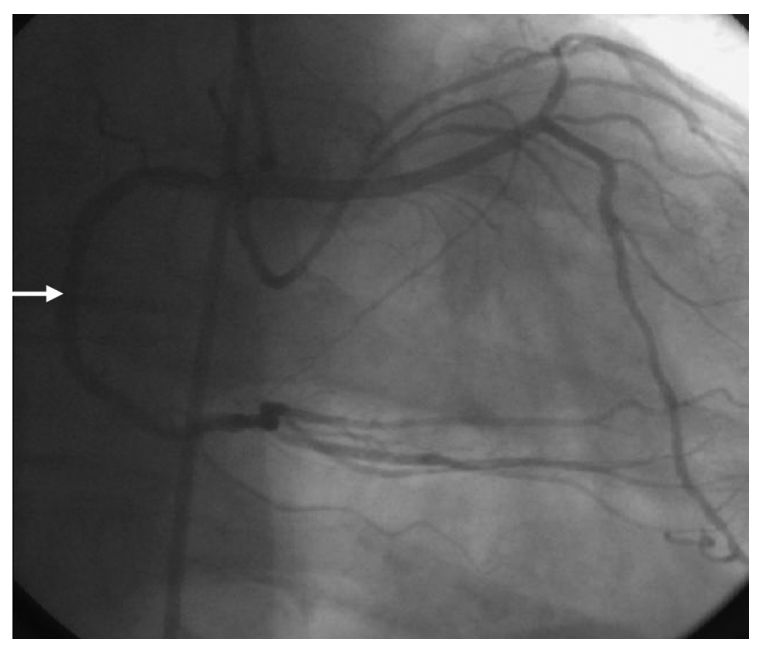

Figure 2 The right coronary artery after a direct stent implantation and the percutaneous transluminal coronary angioplasty.

Vascular Health and Risk Management

\section{Publish your work in this journal}

Vascular Health and Risk Management is an international, peerreviewed journal of therapeutics and risk management, focusing on concise rapid reporting of clinical studies on the processes involved in the maintenance of vascular health; the monitoring, prevention and treatment of vascular disease and its sequelae; and the involvement of that there is an increased risk of atherosclerosis in the case of a single coronary artery, which may result from acute-angle take-off malformation. ${ }^{5}$ Coronary spasm, angina pectoris, and myocardial infarction are also reported in the absence of coronary stenosis. ${ }^{6}$ Gleeson et al have reported a patient with SCA from the right aortic sinus of Valsalva who had significant lesions in right coronary arteries and was treated successfully by PCI. ${ }^{?}$

\section{Conclusion}

We describe a rare case of a patient who had an anomaly of the left and right coronary arteries with a single coronary ostium in the right sinus of Valsalva, in which percutaneous coronary intervention was successfully performed in the right coronary artery. Selecting the appropriate guiding catheter in SCA is commonly difficult due to the tortuous angle and unusual direction of the coronary artery. In addition, if a dissection occurs, it may extend retrogradely and involve the origins of the LMCA and RCA, and the consequences may be serious. Therefore, selecting the appropriate guiding catheter and other equipment is essential to the technical success of the procedure.

\section{Disclosure}

No conflicts of interest were declared in relation to this paper.

\section{References}

1. Yamanaka O, Hobbs RE. Coronary artery anomalies in 126,595 patients undergoing coronary arteriography. Cathet Cardiovasc Diagn. 1990;21:28-40.

2. Desmet W, Vanhaecke J, Vrolix M, et al. Isolated single coronary artery: a review of 50,000 consecutive coronary angiographies. Eur Heart J. 1992;13:1637-1640.

3. Lipton MJ, Barry WH, Obrez I, et al. Isolate single coronary artery: diagnosis, angiographic classification, and clinical significance. Radiology. 1979;130:39-47.

4. Angelini P, Velasco JA, Flamm S. Department of adult cardiology, incidence, pathophysiology and clinical relevance. Circulation. 2002;105:2449-2454.

5. Porto I, Banning AP. Unstable angina in a patient with single coronary artery. Heart. 2004;90:858.

6. Yaymaci B, Ugurlucan M, Basaran M, et al. Solitary coronary artery nourishing the entire heart. Ann Saudi Med. 2010;30:81-83.

7. Gleeson T, Thiessen R, Wood D, Mayo JR. Single coronary artery from the right aortic sinus of Valsalva with anomalous prepulmonic course of the left coronary artery. Can J Cardiol. 2009;25:e136-e138.

\section{Dovepress}

metabolic disorders, particularly diabetes. This journal is indexed on PubMed Central and MedLine. The manuscript management system is completely online and includes a very quick and fair peer-review system, which is all easy to use. Visit http://www.dovepress.com/ testimonials.php to read real quotes from published authors. 